\title{
Creative practice in a group setting
}

\section{Introduction}

The growing popularity of the role of the arts in promoting mental health and well-being is reflected in the proliferation of literature on the subject. Common themes emerging from this literature are that nearly everyone has the capacity to use the arts, that the use of arts extends therapeutic choice and that the arts can empower participants helping to improve their confidence, quality of life, self esteem and social inclusion (Argyle and Bolton, 2004). This role of the arts in promoting social inclusion has been reflected in the growing field of health humanities within mental health practice. In contrast to medical humanities, this is not limited to medical frameworks of understanding and encourages diverse ways of promoting mental health and well-being (Crawford et al., 2015). A corresponding concept is that of 'mutual recovery' which extends the concept of recovery beyond one focusing only on mental health service users to include context, reciprocity and the wider community (Crawford, et al., 2013). For, as previous research has recognised, the incidence of mutuality tends to accelerate the process of mental health recovery (Pernice-Duca, 2010).

As part of the 'Creative Practice as Mutual Recovery Programme' (AHRC), it has been the purpose of an innovative project called 'Clay Transformations' to explore the way in which involvement in clay workshops can promote this mutual recovery amongst diverse groups of participants (Argyle, 2015; Cooper, 2012). With this goal in mind, three blocks of eight week clay workshops which were run with each block being facilitated by two separate artists, Stephen who focused on mask making and maquettes and Sandy who was a more traditional 'potter'. Each block consisted of at least ten voluntary participants. Workshops mainly consisted of mental health service users but, in recognition of the fact that the need for 'recovery' is not just confined to this group (Walker, 2014), others from diverse backgrounds also took part including artists and practitioners.

\section{Methods}

There were a total of 42 workshop participants, the majority were mental health service users (23), others were artists (8), practitioners (4) or had mixed identities (7). Their experiences were evaluated using a mixed methods approach including participant observation, one to one interviews, focus groups, reflective logs and well-being questionnaires. Ethical approval was obtained and issues of informed consent and confidentiality were adhered to throughout the fieldwork. As the incorporation of user perspectives are central to concepts of mutual recovery and the corresponding discipline of health humanities (Crawford et al, 2015), there follows a summary of the qualitative findings of this evaluation. This includes an overview of participant's comments throughout the sessions and the themes emerging from these. This is followed by an in depth account of one mental health service user called 'Jane' on her experiences as a project participant. Such a narrative approach is consistent with the empowering and inclusive practice employed in art for health projects. For as Stacey and Stickley (2010) observe, in an environment where mental health service users have traditionally felt 
oppressed such narrative approaches in research help to redress this oppression, giving them a voice and putting them at 'centre stage'.

\section{Findings}

Participant's motives for taking part in the workshops included to 'relax', 'meet people', 'have fun', 'learn new skills' and become 'creatively unblocked'. Artists and therapists in the groups also wanted to experience a therapeutic intervention from a participant's perspective and in a non-judgemental environment. All claimed to have 'enjoyed' the workshops or found them 'therapeutic':

"I loved the clay workshops and found them very diverting and enjoyable. They definitely had a positive impact on my mood and feeling of well-being while I was doing them"

Within this theme a number of separate issues emerged. Most commonly referred to were the benefits of being in the wider group. For many, this group membership helped to provide structure to their week, combatted social isolation and provided a sense of belonging, mutual interaction and support:

"People have really helped each other, I think that's really good and I feel l've benefitted by not being so socially isolated. So coming out and actually being with people, making a commitment to come out every Monday is a huge thing"

These aspects of mutuality, reciprocity and group cohesion were enhanced by the fact that participants were having a "shared experience":

"I've noticed that because were having a shared experience and working on the same tasks. That does kind of help in getting to know people"

The diversity of group participants and the "openness" of the project artists appeared to further facilitate these processes by minimising the hierarchal divisions that can be apparent in more traditional therapeutic sessions:

"I think it's good for our mental health to have that mix rather than a hierarchy. I think it addresses the power thing that can be an issue"

A further expressed benefit was the experience of working with the clay which was seen to be more accessible and flexible than other forms of creative activity:

"I think you can just pick up some clay and start playing around with it whereas having a blank bit of paper in front of you can be a bit more intimidating"

Related to this was involvement in the process of art creation:

"Coming to each session has given me much needed 'space' to relax, switch off from my anxiety, be creative. Being in a group has been wonderful too"

This focus on process helped to promote a sense of creative freedom and avoided psychotherapeutically orientated interpretations of work which some thought to be unhelpful:

"I think because I was just having a go and not thinking about the finished product it was more fun, free and spontaneous"

In spite of this focus on process the outcome of this work was also seen as important, participants acquired relevant skills giving rise to a sense of achievement. As one participant said of her completed clay creations: 
"They will be a reminder of the eight afternoons I had in the company of a diverse, sociable and interesting group of people who made the whole experience special and something to look forward to every week" A truly therapeutic experience should be one that outlasts the session and this was achieved through such things as enhanced creative confidence, personal and professional networking and development and an increased awareness of relevant opportunities. With these goals in mind, participants in each block were signposted to further relevant courses around the region and many have gone on to further pursue creative activities, while others have formed close and lasting friendships as a result of going to the sessions. As an artist said:

"I loved working with clay and this will inspire my future creative process professionally and therapeutically"

However, some mental health service users expressed regret at the lack of ongoing availability of these types of interventions due to "government cuts":

"Care is generally not adequate now for those who need it most"

'Jane', the participant featured below had formerly worked as a teacher but had been off work for around three years due to her anxiety and depression which she felt had been exacerbated by her experiences at work. In accordance with the close link between social problems and mental health issues, she had also experienced housing difficulties which she thought had further exacerbated her anxiety and depression. Although she had never worked with clay beforehand, she thought that attending the workshops would be an opportunity to "do something entirely different and maybe gain confidence as a result".

"I was recommended to this research project by a support worker, never having done anything 'arty' before but feeling sufficiently well to judge that I could participate. My history was that of recurrent episodes of depression and anxiety and I welcomed the opportunity to try a different form of therapy. I was also keen to contribute to research that might benefit others in the future. On the first day, I had, in common with some of the others, I'm sure, the usual trepidation about social interaction and analysing my own well-being as a bench mark at the beginning of the course. In addition, I worried about whether I had any right to be there, sure that there must be others more deserving of a place. However, tutor, researcher and group members were quite non-threatening and, once we had started working with the clay, I calmed down sufficiently to feel, if not wholly comfortable, at least safe. My flight reflex had subsided.

In that first session came a pivotal idea from Stephen, the mask making tutor, that this was all about the process, not the product. As someone with very little creative ability, this helped me enormously. It meant that I could enjoy 'playing' with the clay and not worry about marks or judgements at the end. A further, intriguing idea was that of manual intelligence and we did finger exercises as a warm up each session to promote this. Thinking of musicians and the speed at which, for example, an accomplished pianist plays, it is obvious that, after a while, the hands know what to do without conscious direction from the brain.

Throughout the sessions, we have developed help and support from and for each other, not only with regard to the work but in other aspects of our lives, 
and some particular bonds have developed. Moreover, one of the joys of being in the class was the pleasure of walking round and viewing the masks of others. There was some astonishing creativity, engendered, no doubt, from innate skill but augmented, possibly, by the reassurance that each person's work had value. In my case, of course, appreciation is a pleasure in itself.

There were other features of the group which I found interesting. In any given week, because of absences, the make up of the group was different and yet the atmosphere remained very positive, comfortable and supportive. In addition, those present always knew who was missing and, sometimes, the reason for their non appearance. This level of intimacy is, I believe, rather unusual in such a newly formed group and is testament to the calming influence of working with clay. Furthermore, conversations in twos and threes, held side by side rather than face to face, were often quite revealing, as if the manual focus on the clay freed the cares of the mind.

As for my feelings about my work, that I could do anything at all came as a complete surprise. I had never thought of myself as being creative in any manual sense. Being able to say that I liked how a finished piece looked was an unexpected delight. It became obvious, in the mask making sessions, that my efforts were suggested by some old memory picture and that others had much more imagination. However, I really did not mind. For me, this comfortable self appraisal was a huge step forward. Crucially, despite the fact that the intent and small amount of imagination far outstripped any capability or skill, this did not matter and actually, I was quite pleased with some of my efforts. Certainly, I was satisfied enough to take photos with my mobile and even showed some to friends and family.

Having never touched clay before, I found it very pleasant to handle but surprising in that it almost forms itself. I loved the fact that, despite having a very clear plan of the finished article, the clay would seem to mould itself into a different shape and become an altogether different mask. By the time we were in Sandy's classes, I was quite willing to let the arbitrary shape of the clay as I rolled, squashed and flattened it dictate the picture that it would finally become. I also appreciated the additional, new ability to appreciate faces: from a tree trunk sculpture in the arboretum; to the woman at the supermarket checkout; to the man sitting opposite on the Barton omnibus. That new fascination will be taken away certainly by me but also, I suspect, by many of the other group members.

In Sandy's classes, we added a new dimension: that of painting the pieces with coloured slip which was so exciting. Some of the group chose to paint directly onto the finished clay but there was another, more delicate technique which I preferred from the outset. This entailed painting colour onto a small piece of newspaper and then, when beginning to dry, applying the paper to the clay, smoothing over it to transfer the paint and then peeling it off. The aim is to build up layers of colour, creating depth, until the desired effect is reached. I particularly liked the gentle blending of colours that could be achieved with this process and have become quite attached to my pieces and started to care about how they will turn out and wanting them to be the best that I can do. 
Both tutors are obviously skilled practitioners but effective teachers as well which, as someone with a background in adult education knows, is not always the case. Also, they have taken on classes of people with mental health issues which some would have found daunting. I've always been nervous of cameras but the photographer, who came to several sessions to take stills and videos of our work in progress, was, by the end, so unobtrusive as to be invisible.

So we have now arrived, all too soon, at the last session and have decided to visit the new arts venue when finished, view the exhibits and get together again as a group. I have looked forward so much to these Monday afternoons and feel as if I have to keep doing this and maybe even other art forms as well. It has been hugely beneficial, more than I ever imagined at the start, a poor, agitated creature, willing myself to leave and never return. A transformation has indeed taken place".

\section{IMAGE 1 HERE}

\section{Discussion}

The qualitative findings presented here reflect many of the benefits of art involvement found in similar studies (Sholt et al., 2006). These expressed benefits included aspects of process, outcome, the unique features of clay work, the experience of being in a group and the potentially sustained impact of involvement. Consequently, in spite of the common debate between the relative therapeutic merits of the involvement in the process of art creation on one hand and in the outcome of this creation on the other (Argyle and Bolton, 2004; 2005), an appreciation of both these aspects were expressed by participants. For example, with regard to outcome, Jane spoke of her "delight" in being able to take pride in her work, while others referred to the acquisition of skills and the memories attached to completed clay work. The process of involvement was seen as being similarly beneficial with the experience of working with clay perceived as being versatile and "pleasant to handle" while the manual focus on the clay "freed the cares of the mind".

These expressed benefits of process and outcome appeared to be facilitated by the fact that the work was taking place in a group and the mutual support, interaction and sense of social belonging arising from this. As such, not only did participants take pride in their own work, they also took pleasure from the mutual admiration of the work of other group members with Jane remarking on their "astonishing creativity". Group interactions also enhanced the experience of the process of art creation with the atmosphere being described by Jane as "positive, comfortable and supportive" and displaying a "level of intimacy" which was perceived to be "unusual in such a newly formed group". As a consequence, she felt that conversations between group members conducted "side by side" during the process of clay work could be quite "revealing". "Helpful and supportive" bonds had subsequently developed "not only with regard to the work but in other aspects of our lives", further highlighting incidence of mutuality and reciprocity within the groups which was seen to be enhanced by their diverse membership and lack of hierarchy. In order for an experience to be truly therapeutic, its impact should be sustained rather than transitory (Argyle and Bolton, 2004). In accordance with this, most 
participants expressed the wish to continue with their creative work and keep in contact with group members, although some lamented the lack of ongoing availability of these types of intervention due to "government cuts":

This role of activity based groupwork in facilitating interaction between group members and in promoting the supportive capacities of the group as a whole has been found to be a major 'curative factor' (Argyle and Bolton, 2004). It also has important implications for mental health promotion. For the presence of such support has been identified as being an important factor in promoting mental health due to the practical and emotional support provided by supportive networks (Stickley and Duncan, 2007). This is particularly the case if these networks are characterised by reciprocity and mutuality in the support provided which has been found to have a positive impact on self perceptions which play a key role in the subjective process of recovery (Pernice-Duca, 2010). The role of groups in providing such support is likely to become increasingly important. This is partly due to trends towards increasing individualism (Phillipson et al., 2004) with community care policy placing great emphasis on individual need and the achievement of independence with little reference to individuals relation to others or their wider social context (Argyle and Bolton, 2004). For example, the 'personalisation' agenda aims to help people stay independent, active and in control of their own lives through the availability of direct payments and individual budgets (Glasby and Littlechild, 2009). However, as Stickley and Duncan (2007) observe, these developments have taken place within the context of cuts to wider health and social care budgets leading to the growing scarcity of community based support services.

As a result of progressive trends in health inequalities (Shaw et al., 2005), social polarisation and the consumerisation of welfare services (Dorling, 2013), this lack of support is likely to disproportionately effect vulnerable groups. For, contrary to the mutually supportive portrayals of working class life traditionally espoused by sociologists (Young and Willmott, 1962) such groups are more likely to be lacking in social networks and social capital more generally (Phillipson et al., 2004) with subsequent implications for their mental health and well-being. When this is combined with the close association between mental health issues on one hand and social problems on the other (Palmer et al., 2002), this can give rise to a dual jeopardy in which adverse mental and social issues become mutually reinforcing. In order, to break this cycle, mental health interventions should aim to transcend their individualised approach and address the wider social contexts that can facilitate or prevent the promotion of mental well-being and 'mutual recovery' (Crawford, et al., 2013). Involvement in creative practice is clearly one means of achieving this, with many community arts projects aiming to promote mental health and social inclusion by attempting to strengthen the social capital of these communities (Wilkinson, 2005). In addition, while the implementation of psychotherapeutically orientated forms of creative practice have tended to be the preserve of those with specialist training, socially orientated art for health interventions are more versatile and are developments in which many practitioners can play a role.

\section{Conclusion}


While involvement in creative practice can be beneficial in itself, the findings presented here suggest that these benefits are enhanced if this practice takes place within a group setting. As such, the supportive capacities of the group can help to promote the 'mutual recovery' of participants and address the social issues that can have a major impact on the promotion of mental wellbeing. These benefits suggest the need for more sustained and widespread funding for this cost-effective, versatile and accessible means of mental health promotion in a community setting. However, the efficacy of these interventions must be proven if appropriate funding is to be obtained and maintained. In this respect, questions still remain on the 'therapeutic' impact of being in a group on one hand and in engaging in creative practice on the other as well as on the relative benefits of different forms of creative practice and the optimal way in which these benefits can be sustained in the longer term.

\section{References}

Argyle, E. and Bolton, G. (2004), The use of art within a groupwork setting, Groupwork, Vol. 14 No. 1, pp. 46-62.

Argyle, E. and Bolton, G. (2005), Art in the community for potentially vulnerable mental health groups, Health Education, Vol 105 No 5, pp. 340354

Argyle, E. (2015), A Potter's Day, Ceramic Review, Vol. 272, p.79.

Cooper, S. J. (2012), Transformations, Ceramic Review, Vol. 254, p.16.

Crawford, P; Lewis, L. Brown, B and Manning, M. (2013), Creative Practice as Mutual recovery in mental health, Mental Health Review Journal, Vol. 18 No. 2, pp. 55-64.

Crawford, P; Brown, B; Baker, C; Tischler, V. and Abrams, B. (2015), Health Humanities, Palgrave Macmillan, Basingstoke.

Dorling, D. (2013), Fairness and the changing fortunes of people in Britain, Journal of the Royal Statistical Society: Series A (Statistics in Society), Vol. 176 No. 1, pp. 97-128.

Glasby, J. and Littlechild, R. (2009), Direct Payments and Personal Budgets, The Policy Press, Bristol.

Palmer, G; Rahman, M. and Kenway, P. (2002), Monitoring poverty and social exclusion, Joseph Rowntree Foundation, York.

Pernice-Duca, F. (2010) Family network support and mental health recovery, Journal of Marital and Family Therapy, Vol. 36 No 1, pp. 13-27.

Phillipson C, Allan G and Morgan D. (eds) (2004), Social networks and social Exclusion, Ashgate, Aldershot.

Shaw, M., Smith, G. and Dorling, D. (2005), Health inequalities and New Labour: how the promises compare with real progress, BMJ, Vol. 330 No. 7498, pp. 1016-1021.

Sholt, M; Gavron, T. and Israel, H. (2006), Therapeutic qualities of clay work in art therapy: a review, Art Therapy: Journal of the American art therapy association, Vol. 13 No. 2, pp. 66-72.

Stacey, G. and Stickley, T. (2007), The meaning of art to people who use mental health services, Perspectives on Public Health, Vol. 130 No 2, pp. 7077. 
Stickley, T. and Duncan, K. (2007), Art in Mind: implementation of a community arts initiative to promote mental health, Journal of Public Mental Health, Vol 6 No 4, pp. 24-32.

Wilkinson, R. (2005), The impact of inequality, The New Press, New York.

Walker, L. (2014), Recovery is for staff not just for people using services, Mental Health and Social Inclusion, Vol. 18 No. 4, pp. 185-187.

Young, M. and Willmott, P. (1962), Family and Kinship in East London, Penguin, Harmondsworth. 